\title{
Maintainability Distribution Model for Laser Inertial Navigation System
}

\author{
Yun Fu*, Jin'e Huang and Zhe He \\ P.O.BOX 1303, Beijing, CHINA \\ ${ }^{*}$ Corresponding author
}

Keywords: Laser inertial navigation, Maintainability distribution model, System level, Device level.

\begin{abstract}
This study builds a maintainability distribution model suitable for laser inertial navigation system beginning with the description of the maintainability index and combining with the characteristics of the system. To enhance the system-level products, the failure rate distribution model is applied, while the weighting factor distribution model of failure rate and design characteristic is applied to the device-level products. Accordingly, these factors providing the basis for the reasonable distribution of maintainability.
\end{abstract}

\section{Introduction}

Maintainability is a type of quality characteristic of an equipment and the attribute provided by the design to make the equipment maintenance simple, rapid, and economical ${ }^{[1-2]}$. The laser inertial navigation system ensures safe navigation during long voyage, dynamic alignment of weapon systems, and stability control of various combat task sensors, thereby making maintainability an important quality characteristic of systems ${ }^{[3-4]}$.

To control the maintainability of the system, the contents of the reliability indexes should be maintained at all levels, while the top-level reliability index should be assigned from top to bottom to each key subsystem. The existing reliability index distribution method is unable to combine the characteristics of the entire subsystem to proceed with a scientific and reasonable index distribution, while the distribution result is difficult to realize in the actual production design or the completed product effect is unable to meet the expected requirements ${ }^{[5-6]}$. This study uses the system-level and device-level maintainability characteristics of an inertial navigation system to introduce different maintainability distribution models and develop a new maintainability distribution method to enhance the existing single distribution method.

\section{Maintainability Distribution Indicator}

The maintainability design and evaluation of a system is an entire and multi-statistic evaluation process. This process means that the evaluation of reliability should undergo product definition, design, development, production, use, and maintenance. Multi-statistic refers to the variety of indicators used to measure and evaluate the reliability of automobiles. Accordingly, many varying statistics can be evaluated. This study evaluates the convenience of statistical indicators and the accuracy of statistical data by mainly using mean time between failure (MTBF) as distribution indicator.

In the prototype stage, the characteristics of a laser inertial navigation system are combined to build a maintainability distribution model that is suitable for this is constructed.

\section{Maintainability Distribution Model}

The maintainability distribution of a laser inertial navigation system is mainly divided into two stages.

First, the laser inertial navigation system maintainability indicators for the system-level distribution are assigned to the three sub-systems of inertial, explicit control transmitter, and power supply devices, which often use the failure rate distribution method.

Second, the distribution value of each sub-system for the device-level distribution is assigned to 
the basic level unit, which often uses the weighted factor distribution method on the basis of the failure rate and design characteristics.

\section{Distribution Model by Failure Rate}

The specific steps of distribution by failure rate are as follows:

1) Determine the failure rate of the $\mathrm{J}^{\text {th }}$ sub-system $\lambda_{j}$;

2) Determine the percentage of the impact of the failure rate of each sub-system on the total failure rate; that is, determine the failure rate weighting factor for each sub-system $W_{j}$ as follows:

$$
W_{j}=\frac{\lambda_{j}}{\sum_{j=1}^{n} \lambda_{j}},
$$

where $\lambda_{j}$ is the failure rate of unit $J$ and $n$ is the number of unit types.

3) Calculate the mean time to repair for each sub-system ${ }^{\bar{M}_{\text {etj }}}$ as follows:

$$
\bar{M}_{c t j}=\frac{\bar{M}_{c t}}{n W_{j}}
$$

\section{Weighting Factor Distribution Model by Failure Rate and Design Characteristics}

The specific steps of the weighting factor distribution method by failure rate and design characteristics are as follows:

1) Analyze the type of product and design characteristics of the product, determine the weighting factors of each unit of the product on the basis of the reference value of the maintainability weighting factor in Table 2, and determine the sum of the $K_{i j}$ weighting factors of each unit on the basis of the following formula $K_{i}$ :

$$
k_{i}=\sum_{j=1}^{m} k_{i j},
$$

where $K_{i j}$ is the weighting factor of the $i^{\text {th }}$ and $\mathrm{j}^{\text {th }}$ units and $\mathrm{m}$ is the number of weighting factor types.

2) Determine the failure rate of each unit of product $\lambda_{i}$.

3) Calculate the mean time to repair unit i as follows:

$$
\bar{M}_{c t i}=\frac{k_{i} \sum_{i=1}^{n} \lambda_{i}}{\lambda_{i} \sum_{i=1}^{n} k_{i}} \bar{M}_{c t},
$$

where $\mathrm{n}$ is the number of unit types. 
Table 1. Reference values of four maintainability weighting factors

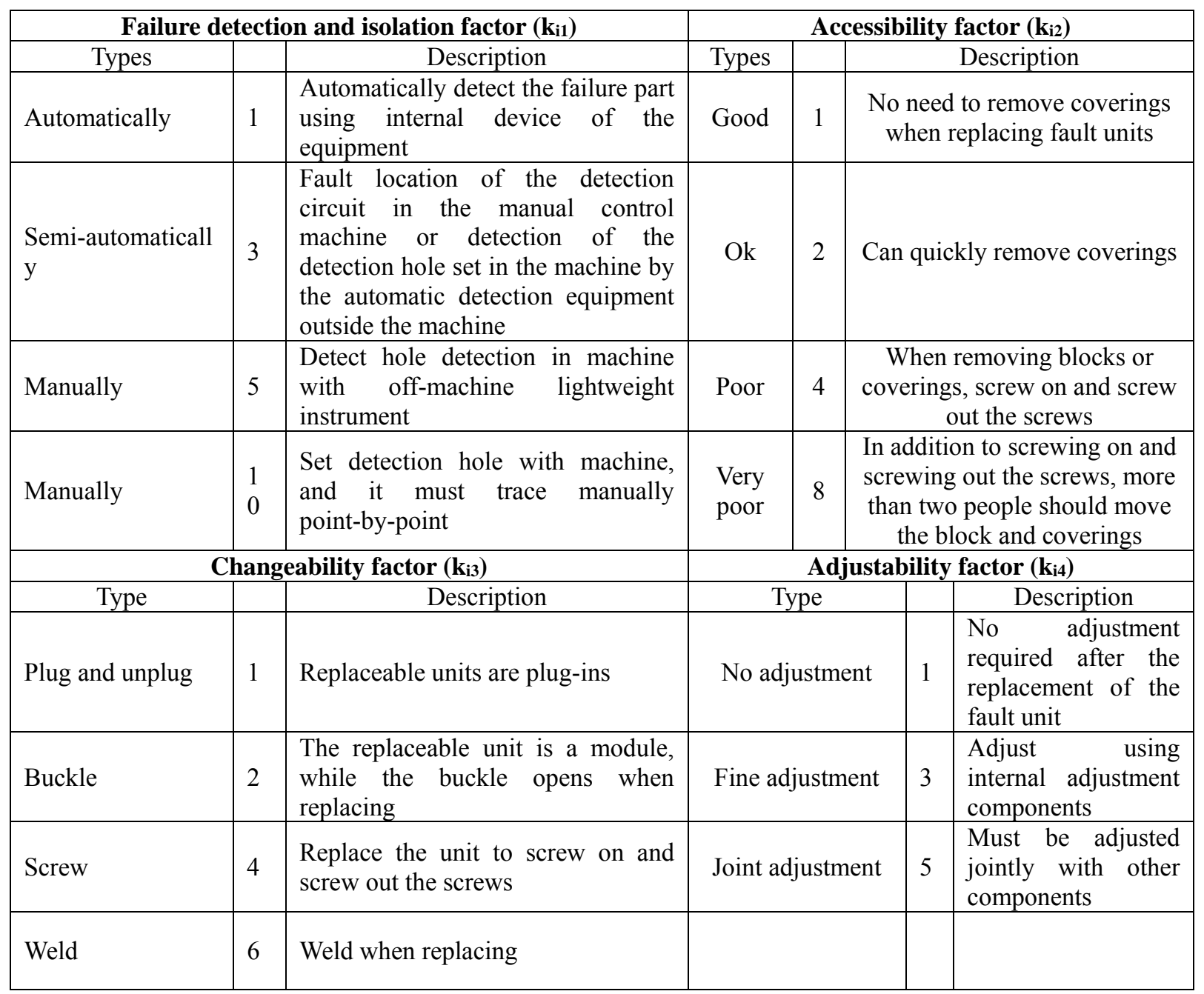

In the prototype stage, the data source is defined, while a comprehensive and detailed maintainability distribution endeavor is conducted at the system and device levels, respectively.

\section{Case Application}

\section{Data Sources}

The failure rate data required in the maintainability distribution are determined on the basis of the relevant reliability analysis data of the inertial navigation system. Table 3 shows the failure rate data of each LRU, in which the power control module temporarily lacks an accurate failure rate data, the failure rate range of the related reference modules is between $5 \times 10^{-6} / \mathrm{h}$ and $10 \times 10^{-6} / \mathrm{h}$, and the boundary failure rate data is considered a $10 \times 10^{-6} / \mathrm{h}$ processing.

In addition, the failure rate data of the inertial device should include the failure rate of the biaxial modulation mechanism and failure rate data of the explicit control transmitter. However, the power supply device should include the failure rate of the internal radiator of the device. The Reliability Analysis Technical Report of the Laser Inertial Navigation System shows that the failure rate of the biaxial modulation mechanism is $37 \times 10^{-6} / \mathrm{h}$. We obtain the radiator failure rate of $2 \times 10^{-6} / \mathrm{h}$ from the electronic system failure rate data in GJB1909.10-1998 Equipment Reliability Maintainability Parameter Selection and Indicator Ddetermination Requirements.

The failure rate of each device is calculated through cumulative correction on the basis of the failure rate data of the LRU component unit. 
Table 2. LRU failure rate data of a laser inertial navigation system

\begin{tabular}{|c|c|c|c|c|c|}
\hline No. & Sub-system & $\begin{array}{c}\text { Sub-system } \\
\text { failure rate } \\
\text { data }\end{array}$ & LRU name & Number $\mathrm{n}$ & $\lambda_{i} \quad(10-6 / h)$ \\
\hline 1 & \multirow{5}{*}{$\begin{array}{l}\text { Inertial } \\
\text { device }\end{array}$} & \multirow{5}{*}{$120.6880 \mathrm{a}$} & IMU & 1 & 58.6098 \\
\hline 2 & & & Angle Measurement Control Module & 1 & 7.5235 \\
\hline 3 & & & Navigation Calculation Module & 1 & 10.0313 \\
\hline 4 & & & Servo Drive Module & 1 & 5.0156 \\
\hline 5 & & & Power Control Module & 1 & 10 \\
\hline 6 & \multirow{8}{*}{$\begin{array}{c}\text { Display } \\
\text { control } \\
\text { transmitter }\end{array}$} & \multirow{8}{*}{$17.0000 \mathrm{~b}$} & Hard Disk Board & 1 & 3 \\
\hline 7 & & & CPU Motherboard & 1 & 1.5 \\
\hline 8 & & & CAN module & 1 & 1.5 \\
\hline 9 & & & $\begin{array}{c}\text { Dual redundant network communication } \\
\text { module }\end{array}$ & 1 & 1.5 \\
\hline 10 & & & Serial port control module & 1 & 1.5 \\
\hline 11 & & & Data Synchronism Forwarding Module & 1 & 1.5 \\
\hline 12 & & & $\begin{array}{l}\text { Reinforcement of computer power } \\
\text { supply }\end{array}$ & 1 & 1.5 \\
\hline 13 & & & Display panel & 1 & 3 \\
\hline 14 & \multirow{5}{*}{$\begin{array}{c}\text { Power } \\
\text { supply unit }\end{array}$} & \multirow{5}{*}{$\begin{array}{l}30.5074^{c} \\
37.0091 d\end{array}$} & $24 \mathrm{~V}$ redundant power supply & 1 & 6.0016 \\
\hline 15 & & & $60 \mathrm{~V}$ redundant power supply & 1 & 6.5017 \\
\hline 16 & & & Excitation power supply & 1 & 7.0018 \\
\hline 17 & & & $\begin{array}{c}\text { Programmable power supply (initial } \\
\text { prototype stage) }\end{array}$ & 1 & 6.5017 \\
\hline 18 & & & UPS power supply & 1 & 9.0023 \\
\hline
\end{tabular}

The weighting factor data of the LRU product is determined on the basis of the design scheme of a product combined with the reference value table of the factor. The quantitative analysis of the principle prototype stage is as follows.

\section{Maintainability Distribution}

System-level Distribution. System-level distribution aims to allocate the maintainability index $(\mathrm{MTTR} \leq 0.5 \mathrm{~h})$ of the laser inertial navigation system to three devices, namely, inertial device, explicit control transmitter, and power supply device, on the basis of the failure rate. The distribution is based on the distribution model by failure rate. Table 3 shows the results of the failure rate data and maintainability distribution.

Table 3. MTTR distribution value of each subsystem of the laser inertial navigation system

\begin{tabular}{|c|c|c|c|c|}
\hline No. & Sub-system & Number & Failure rate $\lambda_{\mathrm{j}}\left(10^{-6} / \mathrm{h}\right)$ & $\overline{\boldsymbol{M}}_{\text {ct } j}$ \\
\hline 1 & Inertial device & 1 & 120.6880 & 14 \\
\hline 2 & $\begin{array}{c}\text { Display control } \\
\text { transmitter }\end{array}$ & 1 & 17.0000 & 103 \\
\hline 3 & Power supply unit & 1 & 30.5074 & 57 \\
\hline
\end{tabular}

Device-level distribution

(1) Inertial device 
Table 4 shows the failure rate data and weighting factor values of each LRU of the inertial device. The distribution results of inertial devices can be obtained on the basis of the failure rate and design characteristic weighting factor distribution method.

Table 4. Inertial device LRU distribution results

\begin{tabular}{|c|c|c|c|c|c|c|c|c|c|c|}
\hline No & Name & LRU name & $\begin{array}{c}\text { Number } \\
n\end{array}$ & $\begin{array}{c}\lambda_{i} \\
(10-6 / \mathrm{h} \\
)\end{array}$ & $\begin{array}{l}\text { Weightin } \\
\mathrm{g} \text { factor } \\
\mathrm{k}_{\mathrm{i} 1}\end{array}$ & $\begin{array}{l}\text { Weightin } \\
\mathrm{g} \text { factor } \\
\mathrm{k}_{\mathrm{i} 2}\end{array}$ & $\begin{array}{l}\text { Weightin } \\
\mathrm{g} \text { factor } \\
\mathrm{k}_{\mathrm{i} 3}\end{array}$ & $\begin{array}{l}\text { Weightin } \\
\mathrm{g} \text { factor } \\
\mathrm{k}_{\mathrm{i} 4}\end{array}$ & $\begin{array}{l}\text { Tota } \\
1 K_{i}\end{array}$ & $\begin{array}{l}\bar{M}_{c t i j} \\
(\mathrm{~min})\end{array}$ \\
\hline 1 & \multirow{5}{*}{$\begin{array}{c}\text { Inerti } \\
\text { al } \\
\text { devic } \\
\text { e }\end{array}$} & IMU & 1 & $\begin{array}{c}58.609 \\
8 \\
\end{array}$ & 1 & 7 & 6 & 3 & 17 & 15 \\
\hline 2 & & $\begin{array}{c}\text { Angle } \\
\text { Measurem } \\
\text { ent Control } \\
\text { Module }\end{array}$ & 1 & 7.5235 & 1 & 4 & 3 & 1 & 9 & 61 \\
\hline 3 & & $\begin{array}{l}\text { Navigation } \\
\text { Calculatio } \\
\text { n Module }\end{array}$ & 1 & $\begin{array}{c}10.031 \\
3\end{array}$ & 1 & 7 & 5 & 1 & 14 & 71 \\
\hline 4 & & $\begin{array}{c}\text { Servo } \\
\text { Drive } \\
\text { Module }\end{array}$ & 1 & 5.0156 & 1 & 4 & 3 & 1 & 9 & 91 \\
\hline 5 & & $\begin{array}{l}\text { Power } \\
\text { Control } \\
\text { Module }\end{array}$ & 1 & $\begin{array}{c}10.000 \\
0\end{array}$ & 1 & 7 & 5 & 1 & 14 & 71 \\
\hline
\end{tabular}

(2) Display control transmitter

Table 5 shows the failure rate data and weighting factor values of each LRU of the display control transmitter. The distribution results of the display control transmitter can be obtained on the basis of the failure rate and design characteristic weighting factor distribution method.

Table 5. Individual LRU distribution result of the display control transmitter

\begin{tabular}{|c|c|c|c|c|c|c|c|c|c|c|}
\hline No & Name & LRU name & $\begin{array}{c}\mathrm{Nu} \\
\mathrm{mbe} \\
\mathrm{rn}\end{array}$ & $\begin{array}{c}\lambda_{\mathrm{i}} \\
\left(10^{-6} / \mathrm{h}\right)\end{array}$ & $\begin{array}{c}\text { Weight } \\
\text { ing } \\
\text { factor } \\
\mathrm{k}_{\mathrm{i} 1} \\
\end{array}$ & $\begin{array}{c}\text { Weight } \\
\text { ing } \\
\text { factor } \\
\mathrm{k}_{\mathrm{i} 2} \\
\end{array}$ & $\begin{array}{c}\text { Weight } \\
\text { ing } \\
\text { factor } \\
\mathrm{k}_{\mathrm{i} 3} \\
\end{array}$ & $\begin{array}{c}\text { Weight } \\
\text { ing } \\
\text { factor } \\
\mathrm{k}_{\mathrm{i} 4} \\
\end{array}$ & $\begin{array}{l}\text { To } \\
\text { tal } \\
\mathrm{K}_{\mathrm{i}}\end{array}$ & $\bar{M}_{c t i j}(\min )$ \\
\hline 1 & \multirow{8}{*}{$\begin{array}{l}\text { Display } \\
\text { control } \\
\text { transmi } \\
\text { tter }\end{array}$} & $\begin{array}{c}\text { Hard disk } \\
\text { board }\end{array}$ & 1 & 3 & 1 & 2 & 1 & 1 & 5 & 6 \\
\hline 2 & & $\begin{array}{c}\mathrm{CPU} \\
\text { motherboard }\end{array}$ & 1 & 1.5 & 1 & 2 & 1 & 1 & 5 & 11 \\
\hline 3 & & CAN module & 1 & 1.5 & 1 & 2 & 1 & 1 & 5 & 11 \\
\hline 4 & & $\begin{array}{c}\text { Dual } \\
\text { redundant } \\
\text { network } \\
\text { communicati } \\
\text { on module }\end{array}$ & 1 & 1.5 & 1 & 2 & 1 & 1 & 5 & 11 \\
\hline 5 & & $\begin{array}{c}\text { Serial port } \\
\text { control } \\
\text { module }\end{array}$ & 1 & 1.5 & 1 & 2 & 1 & 1 & 5 & 11 \\
\hline 6 & & $\begin{array}{c}\text { Data } \\
\text { synchronism } \\
\begin{array}{c}\text { Forwarding } \\
\text { module }\end{array} \\
\end{array}$ & 1 & 1.5 & 1 & 2 & 1 & 1 & 5 & 11 \\
\hline 7 & & $\begin{array}{l}\text { Reinforceme } \\
\text { nt of } \\
\text { computer } \\
\text { power supply }\end{array}$ & 1 & 1.5 & 1 & 2 & 1 & 1 & 5 & 11 \\
\hline 8 & & Display panel & 1 & 3 & 1 & 2 & 6 & 1 & 10 & 11 \\
\hline
\end{tabular}

(3) Power supply unit

Table 6 shows the failure rate data and weighting factor values of each LRU of the power supply unit. The distribution results of the power supply unit can be obtained on the basis of the failure rate and design characteristic weighting factor distribution method. 
Table 6. Individual LRU failure rate data of the power supply unit

\begin{tabular}{|c|c|c|c|c|c|c|c|c|c|c|}
\hline No. & Name & $\begin{array}{l}\text { LRU } \\
\text { name }\end{array}$ & $\underset{n}{\text { Number }}$ & $\begin{array}{c}\lambda_{i} \\
\left(10^{-6} / \mathrm{h}\right)\end{array}$ & $\begin{array}{l}\text { Weighting } \\
\text { factor } \mathrm{k}_{\mathrm{i} 1}\end{array}$ & $\begin{array}{l}\text { Weighting } \\
\text { factor } \mathrm{k}_{\mathrm{i} 2}\end{array}$ & $\begin{array}{l}\text { Weighting } \\
\text { factor } k_{i 3}\end{array}$ & $\begin{array}{l}\text { Weighting } \\
\text { factor } \mathrm{k}_{\mathrm{i} 4}\end{array}$ & $\begin{array}{c}\text { Total } \\
\mathrm{K}_{\mathrm{i}}\end{array}$ & $\begin{array}{l}\bar{M}_{c t i j} \\
(\mathrm{~min})\end{array}$ \\
\hline 1 & \multirow{4}{*}{$\begin{array}{c}\text { Power } \\
\text { supply } \\
\text { unit }\end{array}$} & $\begin{array}{c}24 \mathrm{~V} \\
\text { redundant } \\
\text { power } \\
\text { supply }\end{array}$ & 1 & 6.0016 & 1 & 5 & 5 & 1 & 12 & 30 \\
\hline 2 & & $\begin{array}{l}60 \mathrm{~V} \\
\text { redundant } \\
\text { power } \\
\text { supply }\end{array}$ & 1 & 6.5017 & 1 & 5 & 5 & 1 & 12 & 27 \\
\hline 3 & & $\begin{array}{c}\text { Excitation } \\
\text { power } \\
\text { supply }\end{array}$ & 1 & 7.0018 & 1 & 5 & 4 & 1 & 11 & 23 \\
\hline 4 & & $\begin{array}{c}\text { UPS } \\
\text { power } \\
\text { supply }\end{array}$ & 1 & 9.0023 & 1 & 5 & 6 & 1 & 13 & 21 \\
\hline
\end{tabular}

MTBF, which is a system-level maintainability indicator, is reasonably assigned to each device to clearly evaluate the maintainability of a system. This method is also feasible in engineering applications.

\section{Conclusion}

This study uses the average fault interval MTBF as the maintainability distribution index of a laser inertial navigation system. Accordingly, the use of this index clearly and intuitively reflects the maintainability level of each subsystem and even the unit level products at a certain stage. The reliability distribution method of system-level and device-grade products reasonably and comprehensively distributes the system-level reliability index to the subsystem and unit levels. The result can reflect the importance of a key subsystem to the maintainability of a system and make the maintainability index considerably intuitive in device-level products. These results provide a scientific basis for the evaluation of maintainability.

\section{References}

[1] Gan Maozhi, Fu guangfu, Wang Linshu, et al. GJB2072-94 Maintainability Test and Evaluation [S]. Beijing: Standards Press of China, 1994:10-15.

[2] Lv Chuan. Maintainability Design Analysis and Verification [M]. Beijing: Distribution Department of National Defense Industry Press, 2012:150-160.

[3] Wang Jiaxiao, Chang Tianqing, Zhu Bin, Wang Yuhao. Maintainability Information Analysis of Strapdown Inertial Navigation Syst

em Based on FMECA [J]. JOURNAL OF PROJECTILES, ROCKETS, MISSILES AND GUIDANCE, 2011,31(01):29-32.

[4] Che Guolun. Research on State Monitoring Technology of Laser Gyro Strapdown Inertial Navigation System [D]. National University of Defense Technology, 2002.

[5] He Zhongwu. Research and Application of RCM Technology at Home and Abroad [J]. Aeronautic Standardization \& Quality, 2006(03):38-40.

[6] Wang Changgao. Research on Reliability-centered Maintenance Thought [J]. Journal f Beijing University of Aeronautics and Astronautics (Social Sciences Editon), 1999(01):36-39. 